OPEN ACCESS ISSN 2548-3501 (online) Edited by: Eny Maryanti Reviewed by: Sarwenda $B$.

${ }^{*}$ Correspondence: Lidia Desiana lidiadesiana_uin@radenfat ah.ac.id

Received: 7 April 2021 Accepted: 21 June 2021 Published: 31 July 2021

Citation: Desiana, Alfian, Alfaridzie (2021) Corporate Governance dan Shariah Compliance Terhadap Financial Statement Fraud Pada Bank Umum Syariah

\section{Corporate Governance dan Shariah Compliance Terhadap Financial Statement Fraud Pada Bank Umum Syariah}

\author{
Lidia Desiana*, Dinnul Alfian Akbar, M Rifky Romadhon Alfaridzie \\ Universitas Islama Negeri Raden Fatah Palembang, Indonesia
}

This study tested the Influence of Corporate Governance and Shariah Compliance on Financial Statement Fraud in Sharia Commercial Banks in the Period 2015-2019. Independent variables in this study are Corporate Governance and shariah compliance projected with Islamic Income Ratio, Profit Sharing Ratio and Islamic Investment Ratio. While the dependent variable used is Financial Statement Fraud in sharia commercial banks. The population in this study was all Sharia Commercial Banks (BUS). Sampling techniques using purposive sampling method. The number of samples as many as 12 Islamic commercial banks with a lot of data 60 . The results of this study show islamic income ratio affects Financial Statement Fraud, while Profit Sharing Ratio, Islamic Investment Ratio and Corporate Governance have no effect on Financial Statement Fraud.

Keywords: Corporate Governance, Shariah Compliance, Financial Statement Fraud

Penelitian ini menguji Pengaruh Corporate Governance dan Shariah Compliance Terhadap Financial Statement Fraud Pada Bank Umum Syariah Periode 2015-2019. Variabel independen pada penelitian ini adalah Corporate Governance dan shariah compliance diproksikan dengan Islamic Income Ratio, Profit Sharing Ratio dan Islamic Investment Ratio. Sedangkan variabel dependen yang digunakan adalah Financial Statement Fraud pada bank umum syariah. Populasi pada penelitian ini adalah seluruh Bank Umum Syariah (BUS). Teknik pengambilan sampel menggunakan metode purposive sampling. Jumlah sampel sebanyak 12 bank umum syariah dengan banyak data yaitu 60 . Hasil penelitian ini menunjukkan Islamic Income Ratio berpengaruh terhadap Financial Statement Fraud, sedangkan Profit Sharing Ratio, Islamic Investment Ratio dan Corporate Governance tidak berpengaruh terhadap Financial Statement Fraud.

Keywords: Corporate Governance, Shariah Compliance, Financial Statement Fraud. 


\section{PENDAHULUAN}

Perbankan syariah di Indonesia sedang mengalami perkembangan yang pesat, hal ini berdasarkan kinerja keuangan Bank Umum Syariah (BUS) di Indonesia (Rahmayani, 2017). Tidak jaminan bahwa suatu lembaga yang memiliki unsur syariah didalamnya tidak mengalami kecurangan. Contohnya pada kasus bank Syariah Mandiri dimana ada pihak internal bank yang memberikan pinjaman fiktif sebesar Rp 102 miliar kepada kepada 197 nasabah fiktif di Bank Syariah Mandiri cabang Bogor. Akibatnya BSM mengalami kerugian Rp 59 miliar. Direktorat Reserse Kriminal Polri menetapkan empat tersangka, tiga di antaranya adalah anggota BSM (Rahmayani, 2017). Kasus ini menunjukkan lembaga syariah khususnya bank syariah juga tidak dapat terbebas dari penipuan.

Berikut beberapa kasus financial statement fraud di Perbankan Syariah. Tabel 1 merupakan Kasus Financial Statement Fraud Perbankan Syariah tahun 2015 - 2019.

\section{[Table 1 about here.]}

Kasus financial statement fraud, membuktikan bahwa unsur syariah tidak menjamin bebas dari fraud. Lemahnya tata kelola perusahaan, lemahnya kontrol internal, dan kinerja buruk mengakibatkan penipuan dan kerugian bagi pemilik dan pemerintah. Association of Certified Fraud Examiners (2010), Financial Statement Fraud adalah kesalahan penyajian yang disengaja atau kekeliruan dalam pengungkapan laporan keuangan untuk membohongi bagi para pemangku kepentingan terhadap laporan keuangan. Kecurangan pelaporan keuangan adalah penyajian dan pengungkapan informasi yang disengaja manajemen untuk menyesatkan pengguna laporan keuangan. Maraknya laporan keuangan yang mengandung kecurangan pada perusahaan publik juga menimbulkan kekhawatiran bagi pengguna laporan keuangan seperti auditor, investor, pemberi pinjaman dan pengguna lainnya (Law, 2011)

Menurut Rezaee (2004), financial statement fraud sangat kuat kaitannya dengan pemalsuan pendapatan oleh manajemen untuk membuat suatu perusahaan terlihat lebih baik dibandingkan dengan perusahaan sejenis lainnya. Manipulasi laba, yang digunakan oleh manajemen sebagai gimmick akuntansi, dengan tujuan untuk mencapai hasil yang sejalan dengan harapan harga saham yang lebih tinggi dan kompensasi eksekutif yang lebih tinggi (Rezaee, 2004).

Untuk meminimalkan kecurangan, Hameed et al. (2004) menyarankan Islamic Disclosure Index (IDI), didasarkan pada tiga alat ukur, sharia compliance, corporate governance dan environment disclosure. Oleh sebab perlunya dilakukan penelitian "Pengaruh Corporate Governance dan Shariah Compliance terhadap Financial Statement Fraud Pada Bank Umum Syariah"

Hasil penelitian dari Fadhistri \& Triyanto (2019) yaitu corporate governance berpengaruh terhadap financial statement fraud. Dewi (2018) yaitu corporate governance tidak berpengaruh terhadap financial statement fraud. Mulazid (2016) menemukan bahwa shariah compliance mempengaruhi kecurangan pelaporan keuangan, sedangkan penelitian Mujib (2017) berpendapat bahwa shariah compliance tidak mempengaruhi kecurangan pelaporan keuangan.

Pada penelitian dari Muhammad et al. (2019) menyatakan Profit Sharing Ratio (PSR) mempunyai pengaruh positif terhadap financial statement fraud dan berbanding terbalik dari penelitian H. Najib \& Rini (2016) yang menyatakan Profit Sharing Ratio (PSR) mempunyai pengaruh negatif pada financial statement fraud. Penelitian dari Nusron (2017) menyatakan bahwa Islamic Invesment Ratio (IIR) memiliki pengaruh pada financial statement fraud dan berbanding terbalik dari penelitian Fadhistri \& Triyanto (2019) menyatakan bahwa Islamic Invesment Ratio (IIR) tidak berpengaruh pada financial statement fraud. Penelitian dari Raharjanti \& Muharrami (2020) menyatakan Islamic Income Ratio (ISIR) mempunyai pengaruh pada financial statement fraud dan berbanding terbalik dengan penelitian dari Santika \& Ghofur (2019) yang menyatakan Islamic Income Ratio (ISIR) tidak memiliki pengaruh pada financial statement fraud. Tujuan penelitian yaitu, menganalisis pengaruh Corporate Governance dengan proksi self assessment good corporate governance pada Financial Statement fraud, dan pengaruh Shariah Compliance dengan proksi dengan Islamic Income Ratio (ISIR), Profit Sharing Ratio (PSR) dan Islamic Investment Ratio (IIR) pada Financial Statement fraud. Pada penelitian ini menambahkan variable corporate governance sebagai variable independent.

\section{METODE}

\section{Jenis Penelitian}

Jenis penelitian menggunakan penelitian kuantitatif. Variabel independen penelitian ini, yaitu corporate governance, shariah compliance dan variabel dependen financial statement fraud.

\section{Sumber Data Penelitian}

Data penelitian diperoleh dari situs Otoritas Jasa Keuangan (OJK), yaitu www.ojk.go.id.

\section{Variabel Penelitian}

Variabel independen adalah Corporate Governance diproksikan dari nilai komposit self assessment Good Corporate Governance Bank Umum Syariah dan sharia compliance diproksikan: yang pertama, Islamic Income Ratio (ISIR) yaitu pembagian antara pendapatan halal dengan jumlah pendapatan (Raharjanti \& Muharrami, 2020). Kedua, Profit Sharing Ratio (PSR), pembagian antara pembiayaan bagi hasil dengan total pembiayaan (Muhammad et al., 2019). Ketiga, Islamic Investment Ratio (IIR) yang diukur dengan pembagian investasi halal dengan jumlah investasi (Nusron, 2017).

Variabel dependen penelitian ini, yaitu Financial Statement Fraud diukur dengan dummy, yaitu 1 untuk perusahaan terindikasi financial statement fraud dan 0 apabila perusahaan tidak terindikasi financial statement fraud ( $\underline{\mathrm{H}}$. Najib \& Rini, 2016).

\section{Populasi dan Sampel}

Bank Umum Syariah di Indonesia sebagai populasi pada penelitian ini. Menurut studi (Association of Certified Fraud Examiners, 2010) industri yang sering menjadi korban 
penipuan adalah bank. Teknik pengambilan sampel

dengan non-random yang kriterianya telah disesuaikan.

Kriteria-kriteria tersebut antara lain: Bank Umum Syariah (BUS) yang mempublikasikan laporan keuangan tahunan dan laporan Good Corporate Governance periode tahun 2015-2019. Pada Tabel 2 merupakan sampel bank Syariah yang terpilih.

\section{[Table 2 about here.]}

Berdasarkan tabel nilai Sig. variabel bebas > 0,05, maka dinyatakan tidak terjadi heterokedastisitas.

\section{Teknik Analisis}

Metode analisis data menggunakan analisis regresi linier berganda meliputi asumsi klasik, uji hipotesis dan statistik (Africano, 2020).

\section{Uji Asumsi Klasik}
a. Normalitas
b. Multikolonieritas
c. Heteroskedasitisas
d. Linieritas
e. Autokorelasi

\section{Uji Hipotesis}

Menggunakan persamaan regresi berganda:

$\mathrm{Y}=\mathrm{a}+\beta 1 \mathrm{X} 1+\beta 2 \mathrm{X} 2+\beta 3 \mathrm{X} 3+\beta 4 \mathrm{X} 4+€$

Uji statistik:

a. Uji Signifikansi Simultan (Statistik F)

b. Uji Signifikansi Parsial (Uji Statistik t)

c. Koefisiensi Determinasi (R2)

\section{HASIL DAN PEMBAHASAN}

\section{Uji Asumsi Klasik}

Normalitas

Normalitas dengan metode Jarque-Bera Test. Kemudian nilai JB dibandingkan dengan nilai tabel chi-square (Africano, 2020). Hasil normalitas ditunjukkan pada Tabel 3.

\section{[Table 3 about here.]}

Nilai Jarque Bera (JB) diperoleh dengan persamaan:

$$
\begin{gathered}
J B=\frac{n}{6}\left(S^{2}+\frac{(K-3)^{2}}{4}\right) \\
\mathrm{JB}=36,4072 \\
\mathrm{X}^{2} \text { tabel }=73,311 \text { (dari tabel chi square) }
\end{gathered}
$$

Berdasarkan tabel 3, nilai probabilitas JB lebih besar dari nilai signifikansinya. Nilai statistik JB yaitu $36,4072<$ nilai $x^{2}$ tabel 73,311. Maka data terdistribusi normal.

\section{Multikolinieritas}

Multikolinearitas dilihat dari Tolerance dan VIF. Jika nilai VIF < 10 dan tolerance > 0,1 (Africano, 2020) maka tidak terjadi multikolinieritas. Hasil multikolinieritas ditunjukkan pada Tabel 4.
[Table 4 about here.]

Berdasarkan tabel disimpulkan bahwa tidak terjadi multikolinieritas.

\section{Heterokedastisitas}

Heteroskedastisitas pada penelitian ini menggunakan metode park (Africano, 2020). Hasil heterokedastisitas ditunjukkan pada Tabel 5.

[Table 5 about here.]

Berdasarkan tabel nilai Sig. variabel bebas $>0,05$, maka dinyatakan tidak terjadi heterokedastisitas.

\section{Linieritas}

Uji linieritas dengan metode ramsey, dengan membandingkan nilai $\mathrm{F}$ hitung dengan $\mathrm{F}$ tabel (Africano, 2020). Hasil linearitas ditunjukkan pada Tabel 6.

\section{[Table 6 about here.]}

Pada persamaan regresi diperoleh $\mathrm{R}_{\text {old }}^{2}=0,235$, dan $\mathrm{R}^{2}$ new $=$ 0,898 . Dengan demikian besarnya nilai $\mathrm{F}$ hitung dapat diperoleh:

$$
\begin{gathered}
\mathrm{F}=\frac{\left(R^{2} \text { new }-R^{2} \text { old }\right) / \mathrm{m}}{\left(1-R^{2} \text { new }\right) /(\mathrm{n}-\mathrm{k})} \\
\mathrm{F}=\frac{(0,898-0,235) / 1}{(1-0,898) /(60-5)} \\
\mathrm{F}=357,5 \\
\mathrm{~F}_{\text {tabel }}=4,016
\end{gathered}
$$

Nilai Fhitung $(357,5)>$ Ftabel $(4,016)$ maka dapat disimpulkan model regresi linier.

\section{Autokorelasi}

Autokorelasi dengan Lagrange Multiplier Test atau LM Test (Africano, 2020). Hasil autokorelasi ditunjukkan padaTabel 7.

\section{[Table 7 about here.]}

Nilai $\mathrm{R}^{2}$ digunakan untuk menghitung nilai $\mathrm{x}^{2}$. Jika nilai $\mathrm{x}^{2}$ hitung $\leq \mathrm{x}^{2}$ tabel, maka tidak terjadi autokorelasi. Maka besarnya nilai $\mathrm{x}^{2}$ hitung pada persamaan ini adalah $\mathrm{x}^{2}=(60-$ 1) $\mathrm{x} 0,018=1,062$. Sedangkan $\mathrm{x}^{2}$ tabel dengan $\mathrm{df}=(55$ : $0,05)=73,311$. Jadi $x^{2}$ hitung $1,062<x^{2}$ tabel 73,311, nilai $x^{2}$ hitung $<\mathrm{x}^{2}$ tabel, dapat disimpulkan bahwa tidak terjadi autokorelasi.

\section{Analisis Regresi Linier Berganda}

Hasil analisis regresi linier berganda ditunjukkan pada Tabel 8 .

\section{[Table 8 about here.]}

Berdasarkan Tabel, persamaan regresi linier berganda: $\mathrm{Y}=-13,849+4,529 \mathrm{ICG}+12,852 \mathrm{ISIR}+(-12,140) \mathrm{PSR}$

$$
+4,351 \mathrm{IR}+\mathrm{e}
$$




\section{Uji F}

Hasil uji F ditunjukkan pada Tabel 9.

[Table 9 about here.]

\section{Uji t}

Hasil uji t ditunjukkan pada Tabel 10.

\author{
[Table 10 about here.]
}

Berdasarkan tabel, Good Corporate Governance tidak berpengaruh pada Financial Statement Fraud dengan signifikansi 0,288 >0,05. Islamic Income Ratio (ISIR) memiliki pengaruh pada Financial Statement Fraud dengan signifikansi 0,001 < 0,05. Profit Sharing Ratio (PSR) tidak memiliki pengaruh pada Financial Statement Fraud dengan signifikansi $0,145>0,05$. Islamic Investment Ratio (IIR)tidak memiliki pengaruh pada Financial Statement Fraud dengan signifikansi 0,092>0,05

\section{Uji Koefisien Determinasi}

Untuk mengukur kemampuan model dalam menerangkan variasi variabel independen digunakan koefisien determinasi (Africano, 2020). Nilai $\mathrm{R}^{2}$ yang kecil menunjukkan kemampuan variabel independen dalam menjelaskan variasi variabel dependen sangat terbatas. Adapun hasil dari uji koefisien determinasi terlihat pada tabel 11.

[Table 11 about here.]

Pada tabel diketahui nilai $\mathrm{R}^{2}$ sebesar 0,235 atau $23,5 \%$. Hal ini berarti $23,5 \%$ variasi variabel terikat yaitu Fraud dapat dijelaskan oleh variabel bebas.

\section{Pembahasan Hasil Penelitian Pengaruh Corporate Governance pada Financial Statement Fraud}

Variabel Corporate Governance memiliki pengaruh pada Financial Statement Fraud pada bank syariah. Syarat bagi institusi dalam menerapkan tata kelola perusahaan lebih difokuskan pada akuntabilitas publik yang berkaitan kegiatan operasional bank dengan ketentuan yang telah ditetapkan (Maradita, 2014). Namun pada penerapannya tidak sesuai, terutama bagi bank syariah di Indonesia yang menggunakan prinsip syariah dan masih dalam tahap penyesuaian serta pengembangan, sejalan dengan penelitian Islamic Research \& Training Institute (Wardayati, 2011) yang menemukan di berbagai negera, terutama pada perbankan syariah Indonesia belum menerapkan GCG dengan baik. Selain itu, masih sedikitnya pemahaman SDM tentang mekanisme dan prinsip syariah yang menyebabkan penerapan nilai syariah tidak memadai, akibatnya masyarakat memiliki kesan tidak baik terhadappraktik tata kelola.

In'airat (2015) berpendapat kecurangan tidak dapat dikurangi dengan menerapkan tata kelola perusahaan, Rahmanti (2019) menyatakan bahwa kurangnya pemahaman SDM perbankan syariah tentang sifat syariah menyebabkan
Berdasarkan tabel, nilai $\mathrm{F}$ hitung 4,236 dengan Sig. 0,005. Maka variabel bebas secara bersama miliki pengaruhsignifikan pada variabel Financial Statement Fraud.

belum Hptimalnya bank syariah dan diidentikkan dengan perbankan tradisional.

\section{Pengaruh Sharia Compliance pada Financial Statement Fraud}

Islamic Income Ratio (IsIR) memiliki pengaruh pada Financial Statement Fraud. Sejalan dengan penelitian Falikhatun \& Assegaf (2012) yang menunjukkan rasio pendapatan syariahm e m i 1 i k i pengaruh pada kesehatan keuangan perbankan syariah di Indonesia. Syariah Kepatuhan merupakan tonggak dalam perkembangan bank syariah, yang menjadikan pembeda bank syariah dan bank konvensional. Diperlukan pengawasan syariah oleh Dewan Pengawas Syariah guna menerapkan prinsipsyariah di perbankan (El Junusi, 2012). Penelitian yang dilakukan oleh Rahman \& Anwar (2014) menyimpulkan bahwa sebagian besar bank syariah di Malaysia, Bahrain, Kuwaitdan Yordania memiliki profitabilitas yang lebih tinggi dan kepatuhan Syariah yang lebih baik.

\section{Pengaruh Profit Sharing Ratio (PSR) pada Financial Statement Fraud}

Profit Sharing Ratio (PSR) tidak memiliki pengaruhpada Financial Statement Fraud. Hal ini menunjukkan PSR tidak mampu untuk memprediksi terjadinya internal fraud, karena pembiayaan bagi hasil yang diberikan hanya difungsikan untuk menyalurkan dana bukan sebagai komitmen untuk menjalankan prinsip-prinsip Syariah (Nusron, 2017). Oleh karena itu, tinggi rendahnya rasio bagi hasil tidak memiliki pengaruh terhadap internal fraud.

\section{Pengaruh Islamic Investment Ratio (IIR) pada Financial Statement Fraud}

Islamic Investment Ratio (IIR) tidak memiliki pengaruh pada Financial Statement Fraud pada bank syariah. Investasi bank syariah didominasi oleh investasi berbasis syariah. Namun pada kenyataannya, kecurangan-kecurangan masih terjadi di bank syariah. Mungkin karena aset adalah rekening yang dapat dimanipulasi dan dicuri, sehingga investasi syariah tidak dapat berbuat banyak untuk mengurangi jumlah kecurangan di bank syariah. Sejalan dengan penelitian Rahman \& Anwar (2014) dan Sula et al. (2014) yang menyimpulkan bahwa pada bank syariah fraudulent statement adalah praktik fraud yang paling sering terjadi.

\section{Kesimpulan}

Penelitian bertujuan untuk mengetahui pengaruh corporate governance dan sharia compliance pada Financial Statement Fraud pada bank umum syariah. Pada penelitian ini diperoleh bahwa Corporate Governance tidak memiliki pengaruh pada Financial Statement Fraud, sedangkan Sharia compliance dengan proksi Islamic Income Ratio memiliki pengaruh pada Financial Statement Fraud. Sharia compliance dengan proksi Profit Sharing Ratio tidak memiliki pengaruh pada Financial 
Statement Fraud. Sharia compliance dengan proksi Islamic Investment Ratio tidak memiliki pengaruh pada Financial Statement Fraud pada bank syariah.

\section{REFERENCES}

Aida, R. N. and Rahmawati, E. (2015). Pengaruh Modal Intelektual dan PengungkaAfricano, F. (2020). Ekonometrika: Teori dan Aplikasi dengan SPSS. Rafah Press.

Askirin, Z. (2016). No Title. Teraslampung. https://www.teraslampung.com/gelapkan-uang-rp-2263-miliarpegawai-bank-mandiri-syariah-ditahan-polisi/

Association of Certified Fraud Examiners. (2010). Report to The Nations on Occupational Fraud and Abuse.

Dewi, S. N. (2018). Pengaruh Mekanisme Corporate Governance Terhadap Kemungkinan Terjadinya Fraud (Studi Empiris Pada Perusahaan Perbankan Yang Terdaftar Di Bursa Efek Indonesia). Jurnal Manajemen Bisnis, 4(2), 179-188.

El Junusi, R. (2012). Implementasi Shariah Governance serta Implikasinya terhadap Reputasi dan Kepercayaan Bank Syariah. Al-Tahrir: Jurnal Pemikiran Islam, 12(1), 87-111.

Fadhistri, K. A., \& Triyanto, D. N. (2019). Pengaruh Islamic Corporate Governance Dan Sharia Compliance Terhadap Indikasi Terjadinya Fraud Pada Bank Umum Syariah Di Indonesia (studi Empiris Pada Bank Umum Syariah Periode 2014-2017). EProceedings of Management,6(2).

Falikhatun, \& Assegaf, Y. U. (2012). Bank Syariah Di Indonesia : Ketaatan Pada Prinsip-Prinsip Syariah Dan Kesehatan Finansial. Conferene in Business, Accounting and Management-FE UNISSULA, 1(1), 245-254.

Fauzie, Y. Y., \& Agustiyanti. (2018). No Title. Cnn Indonesia. https://www.cnnindonesia.com/ekonomi/20180214172620-78276222/bank-syariah-mandiri-diduga-beri-pembiayaan-fiktif-rp11-t

Hameed, S. S., Pramano, B. A., \& Bahrom., N. (2004). Alternative Disclosure and Performance for Islamic Bank's. Proceeding of The Second Conference on Administrative Science: Meeting The Challenges of The Globalization Age.

Hozi, A. (2018). No Title. Kompasiana. https://www.kompasiana.com/alihozi77.blogspot.com/5a9b6337f13344 531e1f2163/kecurangan-fraud-yang-bisa-meruntuhkan-perbankansyariah?page $=$ all

In'airat, M. (2015). The Role of Corporate Governance in Fraud Reduction-A Perception Study in the Saudi Arabia Business Environment. Journal of Accounting and Finance, 15(2), 119.

Law, P. (2011). Corporate governance and no fraud occurrence in organizations. Managerial Auditing Journal, 26(6), 501-518.

Maradita, A. (2014). Karakteristik Good Corporate Governance Pada Bank Syariah Dan Bank Konvensional. Yuridika, 29(2), 191-204. https://doi.org/10.20473/ydk.v29i2.366

Muhammad, R., Kusumadewi, R., \& Saleh, S. (2019). Analisis Pengaruh Syari'ah Compliance dan Islamic Corporate Governance terhadap Tindakan Fraud (Studi Empirik pada BUS di Indonesia Periode 2013-2017). IQTISHADIA: Jurnal Ekonomi \& Perbankan Syariah, 6(1), 65. https://doi.org/10.19105/iqtishadia.v6i1.2202

Mujib, A. (2017). Syari' Ah Fraud Model : Sebuah Konsep Dasar. Snaper-Ebis 2017, 2017, 27-28.

Mulazid, A. S. (2016). Pelaksanaan Sharia Complience Pada Bank Syariah( Studi Kasus Pada Bank Syariah Mandiri, Jakarta ). Madania, 20(1), 37-54.

Najib, H., \& Rini. (2016). Analisis Faktor Yang Mempengaruhi Fraud di Bank Syariah. Simposium Nasional Akuntansi XIX. https://doi.org/10.14710/jspi.v13i1.55-73

Nusron, L. A. (2017). Analisis Faktor-faktor yang Mempengaruhi Fraud di Bank Syariah.

Raharjanti, A. I., \& Muharrami, R. S. (2020). The Effect of Good Corporate Governance and Islamicity Financial Performance Index of Internal Fraud Sharia Banking Period 2014-2017. Journal of Business Management Review, 1(1), 061-075. https://doi.org/10.47153/jbmr.v1i1.13

Rahman, R. A., \& Anwar, I. S. K. (2014). Types of Fraud among Islamic Banks in Malaysia. International Journal of Trade, Economics and Finance, 5(2), 176-179. https://doi.org/10.7763/ijtef.2014.v5.365

Rahmanti, V. N. (2019). Mengapa Perbankan Syariah Masih Disamakan Dengan Perbankan Konvensional? IMANENSI: Jurnal Ekonomi, Manajemen Dan Akuntansi Islam, 1(1), 62-74. https://doi.org/10.34202/imanensi.1.1.2013.62-74
Rahmayani. (2017). Pengaruh Islamic Corporate Governance Dan Internal Control Terhadap Indikasi Terjadinya Fraud Pada Bank Umum Syariah Di Indonesia. Jurnal Ilmiah Mahasiswa Ekonomi Akuntansi (JIMEKA), 2(3), 18-38.

Rezaee, Z. (2004). Financial Statement Fraud: Prevention and Detection. In Research in Accounting Regulation (Vol. 17) https://doi.org/10.1016/s1052-0457(04)17015-x

Santika, A., \& Ghofur, R. A. (2019). Pengaruh Syariahcomplaince Terhadap Fraud Pada Bank Umum Syariah Di Indonesia. Jurnal Syarikah, 5(2), 110-116. https://ojs.unida.ac.id/JSEI/article/view/1981/0

Sula, A. E., Alim, M. N., \& Prasetyono. (2014). Pengawasan, Strategi Anti Fraud, Dan Audit Kepatuhan Syariah Sebagai Upaya Fraud Preventive Pada Lembaga Keuangan Syariah. JAFFA Oktobe, 02(2), 91-100.

Wardayati, S. M. (2011). Implikasi Shariah Governance Terhadap Reputasi Dan Kepercayaan Bank Syariah. Walisongo: Jurnal Penelitian Sosial Keagamaan, 19(1), 1. https://doi.org/10.21580/ws.2011.19.1.210

www.ojk.go.id

Copyright (c) 2020 and. This is an open-access article distributed under the terms of the Creative Commons Attribution License (CC BY). The use, distribution or reproduction in other forums is permitted, provided the original author(s) and the copy-rightowner(s) are credited and that the original publication in this journal is cited, in accordance with accepted academic practice. No use, distribution or reproduction is permitted which does not comply with these terms. 


\section{LIST OF TABLES}

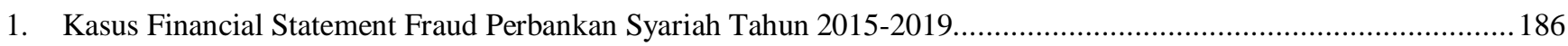

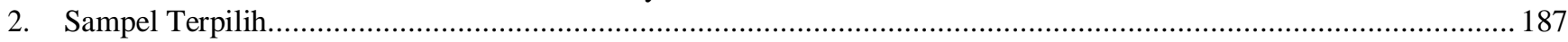

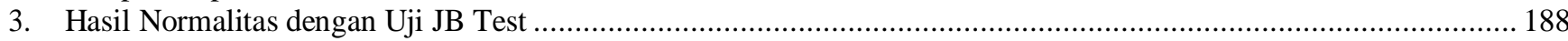

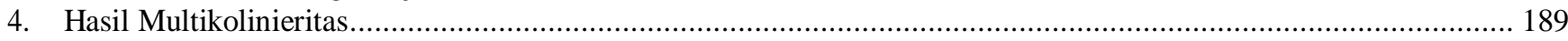

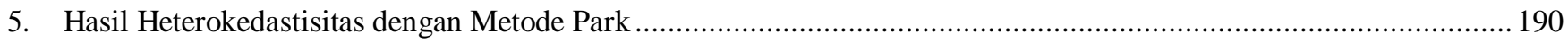

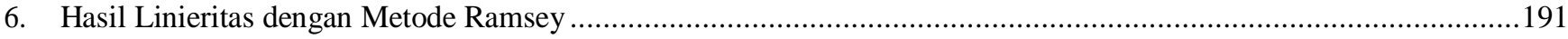

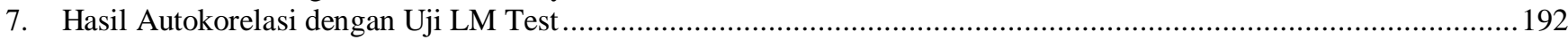

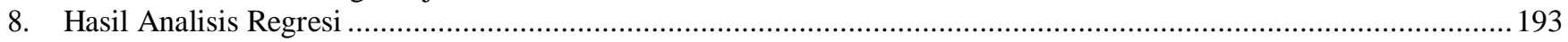

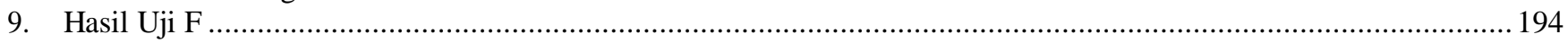

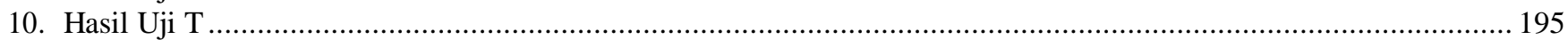

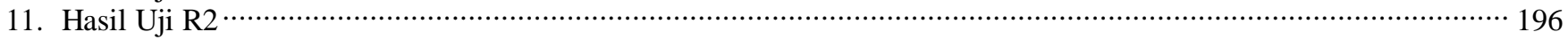


TABLE1 | Kasus Financial Statement Fraud Perbankan Syariah tahun 2015 - 2019

\begin{tabular}{c|l|l}
\hline No. & \multicolumn{1}{|c}{ Kasus } & \multicolumn{1}{c}{ Sumber } \\
\hline 1. & $\begin{array}{l}\text { Penyelewengan uang Rp 2,263 miliar oleh pegawai Bank } \\
\text { Syariah Mandiri ditahan polisi }\end{array}$ & (Askirin, 2016) \\
\hline 2. & $\begin{array}{l}\text { Penipuan pembiayaan pertambangan fiktif Rp100 miliar oleh } \\
\text { bank syariah Maret 2017 }\end{array}$ & (Hozi, 2018) \\
\hline 3. & $\begin{array}{l}\text { Tahun 2018 Bank Mandiri Syariah kembali diduga } \\
\text { menyalurkan pembiayaan fiktif yang berpotensi menimbulkan } \\
\text { kerugian Negara. }\end{array}$ & (Fauzie \& Agustiyanti, 2018) \\
\hline
\end{tabular}


TABLE 2 | Sampel Terpilih

\begin{tabular}{l|l}
\hline 1 & Bank Muamalat Indonesia \\
\hline 2 & Bank Syariah Mandiri \\
\hline 3 & Bank Mega Syariah \\
\hline 4 & Bank BRI Syariah \\
\hline 5 & Bank BNI Syariah \\
\hline 6 & Bank Syariah Bukopin \\
\hline 7 & Bank Jabar Banten Syariah \\
\hline 8 & Bank BCA Syariah \\
\hline 9 & Bank Victoria Syariah \\
\hline 10 & Bank Panin Dubai Syariah \\
\hline 11 & Bank BTPN Syariah \\
\hline 12 & Bank Aceh Syariah \\
\hline
\end{tabular}


TABLE 3 Hasil Normalitas dengan Uji JB Test

\begin{tabular}{c|c|c|c}
\hline \multicolumn{2}{c|}{ Kkewness } & \multicolumn{2}{c}{ Kurtosis } \\
\hline Statistic & Std.eror & Statistic & Std.eror \\
\hline 0,276 & 0,580 & $-0,776$ & 1,121 \\
\hline
\end{tabular}


TABLE 4 | Hasil Multikolinieritas

\begin{tabular}{c|c|c}
\hline \multirow{2}{*}{ Model } & \multicolumn{3}{|c}{ Collinearity Statistics } \\
\cline { 2 - 3 } & Tolerance & VIF \\
\hline GCG & 0,741 & 1,349 \\
\hline ISIR & 0,683 & 1,464 \\
\hline PSR & 0,957 & 1,045 \\
\hline IIR & 0,918 & 1,089 \\
\hline
\end{tabular}


TABLE 5 | Hasil Heterokedastisitas dengan Metode Park

\begin{tabular}{c|c|c}
\hline Model & $\mathrm{t}$ & Sig. \\
\hline GCG & $-1,927$ & 0,083 \\
\hline ISIR & 1,381 & 0,197 \\
\hline PSR & $-0,170$ & 0,869 \\
\hline IIR & 1,305 & 0,221 \\
\hline
\end{tabular}


TABLE6 | Hasil Linieritas dengan Metode Ramsey

\begin{tabular}{c|c}
\hline R Square Old & R Square New \\
\hline 0,235 & 0,898 \\
& \\
\hline
\end{tabular}


TABLE 7 | Hasil Autokorelasi dengan Uji LM Test

R Square

0,018 
TABLE 8 | Hasil Analisis Regresi

\begin{tabular}{c|c|c}
\hline \multirow{2}{*}{ Model } & \multicolumn{2}{|c}{ Unstandardized Coefficients } \\
\cline { 2 - 3 } & B & Std.Eror \\
\hline (Constant) & $-13,849$ & 9,451 \\
\hline GCG & 4,529 & 4,218 \\
\hline ISIR & 12,852 & 3,604 \\
\hline PSR & $-12,140$ & 8,208 \\
\hline IIR & 4,351 & 2,535 \\
\hline
\end{tabular}


$\underline{\text { TABLE } 9 \text { / Hasil Uji F }}$

\begin{tabular}{|c|c|}
\hline $\mathrm{F}$ & Sig \\
\hline 4,236 & 0,005 \\
\hline
\end{tabular}


TABLE 10 / Hasil Uji T

\begin{tabular}{c|c|c}
\hline Variabel & $\mathrm{t}$ & Sig \\
\hline GCG & 1,074 & 0,288 \\
\hline ISIR & 3,566 & 0,001 \\
\hline PSR & $-1,479$ & 0,145 \\
\hline IIR & 1,716 & 0,092 \\
\hline
\end{tabular}


TABLE11 / Hasil Uji R ${ }^{2}$

\begin{tabular}{c|c|c}
\hline $\mathrm{R}$ & R Square & Adjusted R Square \\
\hline $0,485^{\mathrm{a}}$ & 0,236 & 0,180 \\
\hline
\end{tabular}

